\title{
Evaluating Course Syllabus: Basis for Reframing into a Learner-Centered Syllabus for Outcome-Based Nursing Education
}

\author{
Hamdan Albaqawi, PhD, RN \\ Farhan Alshammari, PhD,RN \\ Eddieson Pasay-an, PhD,RN \\ Lecturer,Male Campus, College of Nursing, \\ University of Hail, Kingdom of Saudi Arabia \\ Mansour Alyami, PhD, RN \\ General Director,Academic Affair and Training, \\ Ministry of Health, Kingdom of Saudi Arabia \\ Sandro Villareal, Ed.D,RN \\ Lecturer,Male Campus, College of Nursing, \\ University of Hail, Kingdom of Saudi Arabia \\ Eliezer Dizon,PhD, $R N$ \\ Lecturer,Female Campus, College of Nursing, \\ University of Hail, Kingdom of Saudi Arabia
}

Doi: 10.19044/esj.2018.v14n10p222 URL:http://dx.doi.org/10.19044/esj.2018.v14n10p222

\begin{abstract}
The shift from customary content-based pedagogical to learnercentered practice is imperative in the 21st century. This research aims to evaluate the course syllabus developed by the faculty members and if the syllabus meets the criteria for the learner-centered syllabus. The study employed a quantitative -comparative design to properly represent the phenomenon. The study was conducted at the selected universities in the Kingdom of Saudi Arabia. Overall, the respondents of the study consist of 100 faculty members and the 50 students from the participating universities in the Kingdom of Saudi Arabia. The researchers adapted the learning-focused syllabus instrument to gather the data. Results show that the faculty members rated the learning goals and objectives to moderate (1.58), while students rated it low (1.42). Likewise, the learning assessment revealed a moderate result (1.76) for faculty members and low (1.38) for the students; the learning activities have moderate (1.69) result for the faculty and low (1.36) for the students. As regards scheduling, faculty members and students reported moderate results having a 2.06 and 2.09 respectively. The classroom
\end{abstract}


environment revealed moderate results both the faculty members (1.62) and the students (1.52). Statistically, there is no significant difference on the category of syllabi when faculty respondents were grouped according to years of teaching $(0.699<.05)$, and gender $(0.186<.05)$ but with a significant difference to courses taught $(0.001>.05)$. The findings show that the course syllabus evaluated is in a transitional phase towards learner-centered. As such, the progress of the syllabus is potential to meet the criteria for an outcomebased nursing education. However, the varying results as reported suggest reconciliation of the views of the faculty members and the students.

Keywords: Learner Centered, Syllabus, outcomes based, Transformational

\section{Introduction}

Clear expectations for learning are necessary to frame within the syllabus as education is shifting to outcomes based (Willingham-McLain, 2011). The shifting of customary pedagogical practices to outcomes-based is imperative for the learners to compete in the 21 st century. This shift is, indeed, a very timely where educational institution is expected to prepare and adopt the challenges in the current trending standard. The roles of the learners at present have dramatically changed as they are put in the environment known as learner-centered. Currently, the learning structure strives to produce an empowered, informed, and responsible student by putting them at the center of the classroom. This learner-centered process theoretically embraces continued improvement in the learning quality. -While it is a learner-centered, the learners need to involve in the decision-making which inspired them to increase their sense of responsibility (Ma \& Gao, 2010; Bovill, Morss, \& Bulley, 2008; Weimer, 2002; Shor, 1996). Such premise will take place in the learner-centered syllabus as one way of contract with the teacher and the learners. A learner-centered syllabus is a productive tool that can ease this transformation from teaching to learner-centered classrooms. This is primarily to discuss the need of learners and allows learners to take charge of their learning that eventually leads to tangible and visible results (Habanek, 2005). Moreover, it is an instrument to inspire learner attitudes, viewpoints, and motivation for learning (Parkes, \& Harris, 2002; Weimer, 2002; Bain, 2004; Brigham Young University Center for Teaching and Learning,N.D; Grunert O'Brien,Mills， \& Cohen,2008). Researchers like Cullen and Harris (2009) view syllabi as strategies for finding the facilitators' reason to make a learner-centered environment in the classroom. Moreover, syllabus is viewed as a contract between the teacher and the learners (Eberly, Newton, Wiggins, 2001; Habanek, 2005; Boysen, Richmond, \& Gurung,2015 ). To Robinson, Wolf, Czekanski, and Dillon (2014) syllabus 
defines and establishes the respective duties, roles, and responsibilities of the learners and the teacher.

While educators have clearly established the purposes of the syllabus in the learning environment, it deems necessary to deliberate and develop syllabus in an institutional context. Eberly, et.al. (2001) found that many of the syllabus they inspected served only as clerical record and were considered to be topically expansive. Singham (2007) further explains that there is a commonness of syllabi as "rule infested, punitive and controlling", and that appears confusing the learners. Moreover, an assessment of the course syllabi also disclosed that almost half of the faculty did not include most of the recommended components (Phwandaphwanda, 2003). Lin's (2010) inferred that focusing on assessment of the syllabi reflects medium congruence with the learning-centered syllabus template. Willingham-McLain (2011) likewise stated that strong syllabi show that instructors have thought through the ways in which they expect students to learn. This includes the methods they use to diagnose and check student learning, and the connection they see between their course and the university's mission. On the other hand, Palmer, Bach, and Streifer (2014) designed a rubric to assess the degree to which a syllabus achieves a learning-centered orientation quantitatively and qualitatively. The rubric focuses on four criteria typical of learning-centered syllabi: the learning goals and aims; the assessment activities, schedule, and overall learning environment. Accordingly, these criteria do not map with any specific section of a syllabus, however, except for the schedule; instead, users are directed to search for quality evidence on all criteria across the syllabus. The researchers used the foregoing premises as a framework for conducting this study on how to develop a learner-centered syllabus for an outcome-based nursing education.

This research is noteworthy to take off as it gives emphasis on designing the learner-centered environment that translates into the nursing practice. It aims to search for the quality evidence of all criteria across the syllabus. A careful comprehension of designing learning environment will direct the learning to focus on with the students. As such, it requires the facilitator to consider the more extensive picture when creating a guideline to adequately meet learning goals and results (Michael, 2015). This study is of paramount importance to those who commit to redesigning course syllabi for the benefit not just of the learner but also of the faculty. Also, nursing instructors who need to give future nurses a dynamic learning atmosphere that puts a premium on positive learning experiences and outcomes, and nursing students who need to experience authentic learning. With these, this study finds the agreement among nursing faculty affiliated with Saudi Higher Education Institutions (HEI) about the learner-centered environment. This includes curricula component integration within the undergraduate nursing 
program and whether the current curriculum can work to address these components. The results of the study serve as a basis for reforming the syllabus to a more transformational towards a learner-centered environment. Generally, this research aims to assess the course syllabus developed by the faculty members, and if it meets the criteria for the learner-centered syllabus. The result of the assessment is a basis for framing a learner-centered syllabus in an outcome-based nursing education. Specifically, it sought to find the level of development of the learner-centered syllabus for nursing along the following dimension: learning goals and goals; learning assessments; schedule and classroom environment; and, learning activities. Lastly, it aimed to look into the differences in the strength of evidence when the faculty respondents are grouped according to age, years of teaching, and the course taught.

\section{Methods}

The researchers employed a quantitative-comparative design to properly represent the phenomenon. The study was conducted at the five selected universities in the Kingdom of Saudi Arabia. The respondents of the study consist of 100 members and 50 students from the College of Nursing at five participating universities in the Kingdom of Saudi Arabia.

The respondents were categorized into two groups: the faculty members who developed their own syllabus and the students as the end-user of the syllabus. The faculty member respondents were chosen through a simple random sampling through; defining the population, setting the sample size, listing the population, allocating the number, finding random numbers and selecting the sample. For the students, they were randomly picked by the researchers.

\section{Instrument}

A learning-focused syllabus rubric was used (Palmer, Bach, \& Streifer, 2014) to gather data for this research. The tool (rubric) is an assessment which provided qualitative descriptions of components that distinguished learningfocused syllabi and used a quantitative scoring system that placed syllabi on a spectrum from content-focused to learning-focused. This rubric was developed to help in assessing to which degree a syllabus achieved a learningcentered orientation. The rubric focused on four areas: (1) Learning goals and goals, (2) assessment of activities, (3) schedule, and (4) overall learning environment. Each area was divided into multiple components reflecting what this area should look like. The respondents identified the degree they considered to have enough evidence for each area in the syllabi, by scoring the items as 1 - "strong evidence", 2 - "moderate evidence" and, 3 - "low evidence". 


\section{Ethical Consideration}

Since this research is more comparative in nature, the researchers have coded the name of the universities using numbers (University 1 , University 2, University 3, etc...). Consent from the participants has appropriately sought. The faculty members and the students as participants were also fully informed about their right to refuse to get involved in the study without any unfavorable consequences.

\section{Data Analyses}

The data gathered were processed through SPSS Version 21. The demographic profile was treated using frequency count and percentage. Weighted mean was used to find the extent of their agreement with the statement. The year and course thought were treated with F-test (oneway ANOVA), while T-Test was used to test the significant difference for gender.

\section{Results}

Table 1 presents the profile data of the faculty member respondents. Most of the faculty members $(53 \%)$ have four-year experience, some have taught for three years $(28 \%)$, and less have a two-year experience (19). Majority of the faculty members were females (64\%), followed by a male with $36 \%$. As regards to the courses taught by the faculty members, most of them taught Research (17\%), Fundamental of Nursing 2(17\%), and Maternal- Child Nursing (17\%). The Pediatric Nursing and Fundamental of Nursing 1 have $12 \%$ each, however, $9 \%$ of the total population of the faculty members has taught Nursing Leadership and Management. Moreover, less of the faculty members have taught the Advance Critical Nursing with $7 \%$ and Community Health Nursing has a $4 \%$ share.

Table 1. Profile of the Faculty Member Respondents

\begin{tabular}{cccc}
\hline Profile & & f & $\%$ \\
\hline Years of Experience & 2 & 19 & 19 \\
& 3 & 28 & 28 \\
Gender & 4 & 53 & 53 \\
& Male & 36 & 36 \\
Course taught & Female & 64 & 64 \\
& Pediatric Nursing & 12 & 12 \\
& Research & 17 & 17 \\
& Fundamental of Nursing 1 & 12 & 12 \\
& Fundamental of Nursing 2 & 17 & 17 \\
& Maternal \& Child Nursing & 17 & 17 \\
& Critical Care Nursing & 5 & 5 \\
& Nursing Leadership and Management & 9 & 9 \\
& Advance Critical Nursing & 7 & 7 \\
& Community & 4 & 4 \\
\hline
\end{tabular}


Generally, the syllabus is perceived to be utilized to a great extent but still requires improvement in terms of its general use showing a moderate result of 1.74 both from faculty and the students. The faculty members rated the learning goals and objectives to moderate (1.58), while students rated it low (1.42). Likewise, the learning assessment revealed moderate result (1.76) for faculty members and low (1.38) for the students; the learning activity has moderate (1.69) result for the faculty and low (1.36) for the students. As regards scheduling, faculty members and students reported moderate results having a 2.06 and 2.09 respectively. The classroom environment revealed moderate results both the faculty members with 1.62, and 1.52 for the students (See Table 2).

Table 2. Category (level) of the Syllabus as rated by the Faculty members and the students

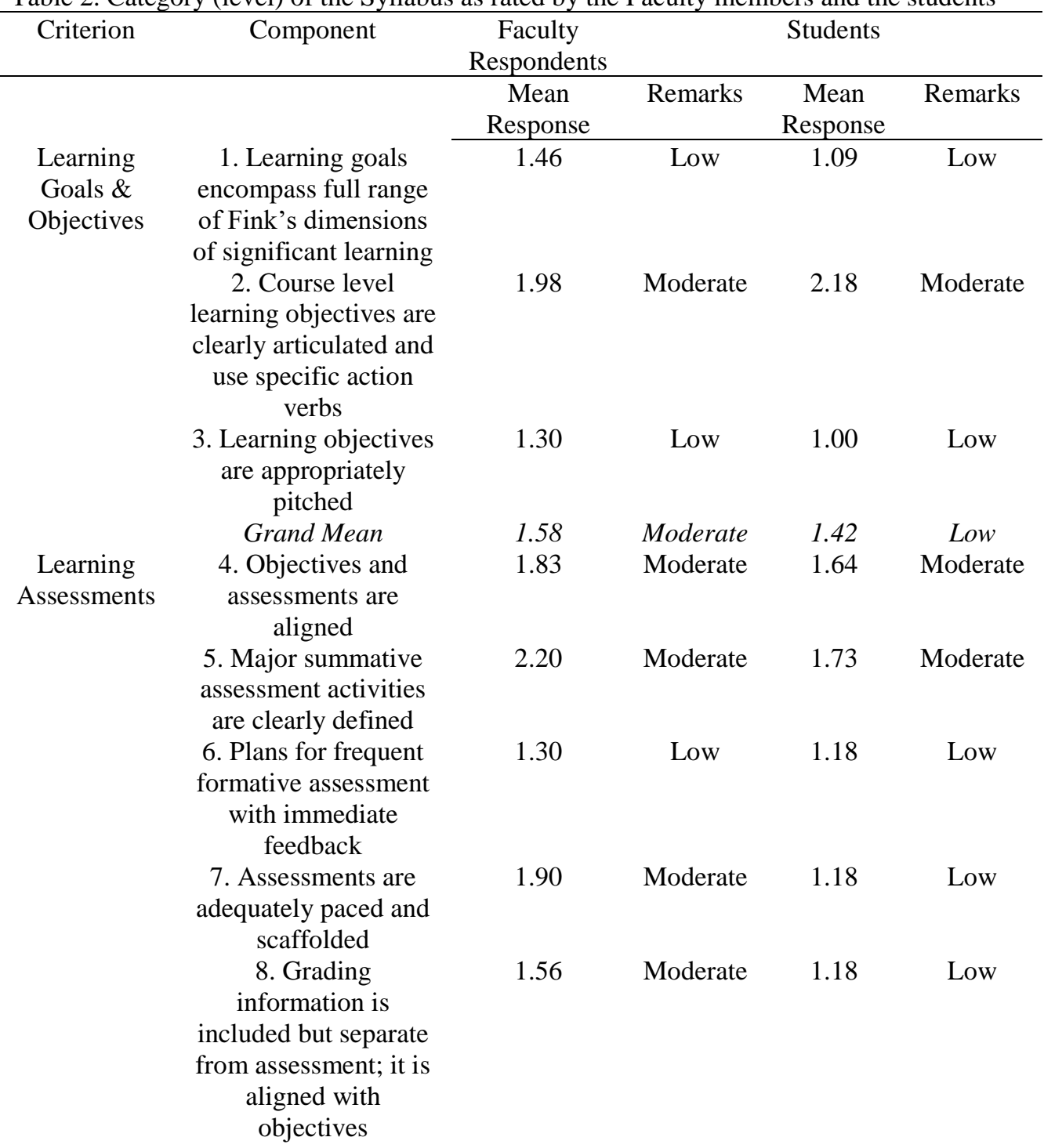




\section{Grand Mean}

Schedule

Classroom Environment

Learning

Activities
9. Course schedule is fully articulated and logically sequenced

10. Tone is positive, respectful, inviting

11. Fosters positive motivation, describes value of course, promotes content as a vehicle for learning

12. Communicates high expectations, projects confidence of success

13. Syllabus is well organized, easy to navigate, requires interaction Grand Mean

\section{Classroom} activities, assessments, and objectives are aligned 15. Learning activities are derived from evidence-based practices

16. Learning activities likely to actively engage students Grand Mean

\subsection{6}

2.06

1.69

1.74

Moderate

1.36

Low

1.38

Low

$$
\text { Moderate }
$$

2.09
Moderate

Low

1.18

Low

1.65

Moderate

1.55

Moderate

1.62

Moderate

1.52

Moderate

1.76

Moderate

1.82

Moderate

Moderate

1.18

Low

1.49

Low

1.09

Low

Overall Grand Mean

\subsection{9}

Moderate

1.36

Low
Moderate 1.74 Moderate

Legend:

$\begin{array}{ll}1.00-1.50 & \text { Low } \\ 1.51-2.50 & \text { Average/Moderate } \\ 2.51-3.00 & \text { Strong }\end{array}$

Table 3 reflects the difference in the category of the syllabus when faculty respondents are grouped according to the profile. It can be gleaned that the years of teaching yielded no significant difference $(0.699<.05)$. Likewise, the gender shows no significant difference as evidence by a higher $\mathrm{p}$-value compared to.05 level of significance. On the other hand, the courses taught by 
the faculty members show a significant difference having a p-value of 0.001 compared to.05 level of significance.

Table 3. Difference in the category of the syllabus when faculty-respondents are grouped according to professional profile.

\begin{tabular}{ccccc}
\hline & Profile & $\begin{array}{c}\text { Mean } \\
\text { Response }\end{array}$ & P-value & Remarks \\
$\begin{array}{c}\text { Year of } \\
\text { experience }\end{array}$ & 2 & 1.77 & 0.699 & Not Significant \\
& 3 & & & \\
Gender & 4 & 1.74 & & Not Significant \\
Course Taught & Female & 1.72 & & \\
& Male & 1.76 & 0.186 & \\
& Basic & 1.99 & 0.001 & \\
& Pediatric & 1.73 & & \\
& Research & 1.62 & & \\
& Fundamental 1 & 1.86 & & \\
& Fundamental 2 & 1.69 & & \\
Maternity & 1.81 & & \\
& Critical Care & 1.92 & & \\
& Nursing Leadership & 1.65 & & \\
\& Management & & & \\
& Advance & 1.81 & & \\
& Community & 1.71 & & \\
& Medical Surgical & 1.67 & & \\
Mental & 1.52 & &
\end{tabular}

Table 4 shows the difference in the category of the syllabus as rated by the faculty members and student evaluators. As seen in the table, their responses yielded a t-value of 2.640 with a P-value of 0.009. Since the Pvalue is less than 0.05 level of significance, this means that there is a significant difference on the category of the syllabus as rated by the faculty and the student evaluators. This implies that the faculty and evaluators have varied ratings on the category of the syllabus. The faculty rated more highly the syllabus than the student evaluators. The result suggests that faculty and the student evaluators have different perspective and standards as regards category of syllabus. Although both groups of respondents are concerned with the needs of learners, there exists slight difference along certain areas. 
Table 4. Significant Difference in the Category of the Syllabus when rated by the Faculty and Students

\begin{tabular}{ccccc}
\hline Respondents & $\begin{array}{c}\text { Mean } \\
\text { Response }\end{array}$ & t-value & P-value & Remarks \\
\hline Faculty & 1.74 & 2.640 & 0.009 & Significant \\
Students & 1.56 & & & \\
\hline
\end{tabular}

\section{Discussions}

The low to moderate variations on the ratings of the two groups of respondents suggest that there is much to do to improve the syllabus. It is of paramount importance to note that syllabus is a document that sends a strong message to learners. As such, this serves as the learners' guide to meet what is expected of them. Indeed, it is clearly important to let learners understand the intentions that are accomplished by way of well-planned and well-written syllabus distributed to learners. Accordingly, the learners acquire more knowledge successfully when intentions and expectations of the facilitator about the courses have been fully understood (Habanek, 2005). Consequently, the learning objectives of the syllabus in this study are believed to be set and clear reported as moderate. While the faculty member has set clear learning objectives, learners may then assess their own learning improvement. It has been concluded by Ludwig, Bentz, and Fynewever (2011) that to become an active and independent learner, one must understand the learning objectives and feedback mechanisms to self-assess one's progress. In a study of Saville and colleagues (2006) learners who obtained a precise and detailed syllabus (including learner-centered elements) recognized the facilitator as possessing much higher levels of master-teacher behaviors.

The transitional stage of the syllabus as reported serves as a springboard towards an appreciative response to the teaching success. This at the end can use to advance and facilitators' professional skills. Strong syllabi show that instructors have thought through the ways in which they expect students to learn. As such, it includes the methods used to diagnose and test student learning, and the connection they see between their course and their university's mission (Willingham-McLain, 2011). Of interest in the results of this study, it shows that the faculty members sustained commitment to align all the learning activities with the outcomes that are expected from the students. In the long run, this increases their rating from moderate to high as they aspire to give more challenges and opportunities for the students to meet the set outcomes. As Killen (2007) stated that what is most significant to the learners is to engage in a challenging task that helps them to discover and develop the best of their ability. According to Emes and Martha (2003), learner-centered curriculum creates highly developed students. As such, it gives skills in the pursuit of creating learning experiences and abstracting present knowledge within the curriculum. 
On the other hand, little research explicitly investigates the view of the students about the syllabus. Learners are the end-user of the syllabus, such that their involvement in the syllabus development should take place. The low to moderate results evaluation reported by the students imply that learners view the syllabus as transitional and there needs to figure out their own learning. As Davis and Shrader (2009) mentioned, learners preferred a syllabus with a learner-centered approach. Further, fostering the involvement of the learners to in the development of, and assessment of the syllabus is recommended considering the tone and respect to the learners. As explained by Baeten, Struyven, and Dochy (2013), the facilitator who is focuses on learner-centered approach gives students opportunities to explore topics of interest in-depth by adhering less strictly to course content. This current result indeed serves as a basis for framing the syllabus to a more transformational syllabus towards a learner-centered environment.

\section{Conclusion}

The findings show that the course syllabus assessed is in the transitional phase towards learner-centered. As such, the progress of the syllabus evaluated is potential to advance and meet the criteria for an outcomebased nursing education. However, the varying results as reported suggest reconciliation of the views of the faculty members and the students.

\section{References:}

1. Baeten, M., Struyven, K., \& Dochy, F. (2013). Student-centred teaching methods: Can they optimise students' approaches to learning in professional higher education? Studies in Educational Evaluation. ( 39): 14-22. doi:10.1016/j.stueduc.2012.11.001

2. Bain, K. (2004). What the best college teachers do. Cambridge MA: Harvard University Press.

3. Bovill, C., Morss, K., \& Bulley, C. (2008). Quality enhancement themes: The first year experience. Mansfield, UK: Quality Assurance Agency fo Higher Education. Retrieved from http://www.enhancementthemes.ac.uk/docs/publications/the-first year-experience curriculum-designfor-the-first-year.pdf

4. Boysen, G., Richmond, A., \& Gurung, R. (2015). Model teaching criteria for psychology: Initial documentation of teachers' selfreported competency. Scholarship of Teaching and Learning in Psychology. 1, 48-59. doi:10.1037/st10000023.

5. Brigham Young University Center for Teaching and Learning Designing a course syllabus: A learning-centered approach. N.D; Retrieved May 31, 2016 from 
http://ctl.byu.edu/sites/default/files/designinga coursesyllabus_0.pdf

6. Cullen, R. \& Harris, M. (2009). Assessing learner-centredness through course syllabi. Assessment and Evaluation in Higher Education. 34(1): 115-125.

7. Eberly, M. B., Newton, S. E., \& Wiggins, R. A. (2001). The syllabus as a tool for student centered learning. The Journal of General Education, 50(1): 56-74.

8. Emes, Claudia, Martha Cleveland-Innes. (2003). “A Journey Toward Learner-Centered Curriculum." The Canadian Journal of Higher Education. Volume 33 (3), p.47-70

9. Fink, S. B.(2012). The many purposes of course syllabi: Which are essential and useful. Syllabus. 1(1).

10. Grunert O’Brien, J. G., Mills, B. J., \& Cohen, M.W. (2008). The course syllabus: A learning centered approach. (2nd ed.). San Francisco: Jossey-Bass.

11. Habanek, D. V. (2005). An examination of the integrity of the syllabus. College Teaching.53 (2), 6264.

12. Killen, R. (2007). Teaching Strategies for Outcomes-Based Education ( $2^{\text {nd }}$ Edition). Cape Town: Juta.

13. Lin, B. (2010). An Assessment of Undergraduate Course Syllabi in the Departments of English at Universities in Taiwan. Dissertation. http://search.proquest.com/docview/749012444/83240D68EE6A4FC $\mathrm{PQ} / 3$ ?accountid $=\quad 5493$

14. Ludwig,M., Bentz, A., \& Fynewever, H. (2011).Your Syllabus Should Set the Stage for Assessment for Learning. Journal of College Science Teaching.40 (4) Retrieved from: https://www.calvin.edu/academic/chemistry/faculty/fynewever Publications/Ludwi JOCST11.pdf

15. Ma, Z., \& Gao, P. (2010). Promoting learner autonomy through developing process syllabus syllabus negotiation: The basis of learner autonomy. Journal of Language Teaching and Research. 1(6): 901-908. doi:10.4304/jltr.1.6.901-908

16. Michael, R.K. (2015). Evaluating Nursing Syllabi for Propensity to Employ Learning Environment Design Principles. The University of Alabama. ProQuest Dissertations Publishing.

17. Palmer, M. S., Bach, D. J., \& Streifer, A. C. (2014).Measuring the promise: A learning focused syllabus rubric. To improve the academy: A journal of educational development. 33 (1), 14-36.

18. Parkes, J., \& Harris, M. B. (2002). The purposes of a syllabus. College Teaching. 50(2): 55-61. 
19. Phwandaphwanda, K. (2003). An assessment of undergraduate course syllabiat the University of Arkansas. University of Arkansas. Dissertation Retrieved from;

20. http://search.proquest.com/docview/305341747/83240D68EE6A4F9 $\mathrm{CPQ} / 1$ ? accountid $=35493$.

21. Robinson Wolf, Z., Czekanski, K. E., \& Dillon, P. M. (2014). Course syllabi: Components and outcomes assessment. Journal of Nursing Education and Practice, 4(1), 100-107. doi:10.5430/jnep.v4n1p100

22. Saville, B., Zinn, T., Neef, N., Van Norman, R., \& Ferreri, S. (2006). Comparison of inter-teaching and lecture in the college classroom. Journal of Applied Behavior Analysis. 39: 49-61.

23. Shor, I. (1996). When students have power: Negotiating authority in a critical pedagogy. Chicago, IL: University of Chicago Press.

24. Singham, M. (2007). Death to the syllabus. Liberal Education. 93(4), Retrieved from http://www.aacu.org/liberaleducation/lefa07/le fa07_myview.cfm

25. Weimer, M. (2002). Learner-centered teaching: Five key changes to practice. San Francisco, CA: John Wiley \& Sons.

26. Willingham-McLain, L. (2011). Using a University-Wide syllabus study to examine learning outcomes and assessment. The Journal of Faculty Development.25(1): 43-53. 